\title{
MEDIA SOSIAL, WORD OF MOUTH DAN PHYSICAL ENVIRONMENT TERHADAP PROSES KEPUTUSAN PEMBELIAN
}

Submitted Date :

4 Desember 2020

\author{
Universitas Merdeka Malang
}

Debby Suryana

Accepted Date :

20 Januari 2021

\section{Suggested Citation:}

Babin, Barry J., L Kong Kie, Kum, EunFu and Griffin, Mitch. (2005).Modelling consumer satisfaction \& word of mouth communication : Restorant Petronage Korea. Journal of Services Marketing Vol.19 pp 133-139. Baker, Julie. The Role of The Environment in Marketing Sevices : The Consumer Perspective. Chicago, IL : American Marketing Association

Abstract:

The purpose of this research are to analyze the influence of social media, word of mouth and physical environment on purchasing decision processes, and to analyze the dominant variables between social media, word of mouth, and physical environment for the purchasing decision process. The number of respondents in this study is 138 people. The data obtained analyzed using multiple linear regression analysis. The results showed that social media, word of mouth and physical environment had a significant effect on the purchasing decision process. Based on the results of multiple regression analysis, it can be seen that the largest regression coefficient value is the physical environment, this means that the physical environment is a variable that has a dominant influence on the purchasing decision process, followed by word of mouth and social media variables.

\section{Abstrak:}

Penelitian ini bertujuan menganalisis pengaruh media sosial, word of mouth dan physical environment terhadap proses keputusan pembelian, serta Menganalisis pengaruh variabel yang dominan antara media sosial, word of mouth, dan physical environment terhadap proses keputusan pembelian. Jumlah responden yang diteliti di dalam penelitian ini adalah 138 orang. Data yang diperoleh selanjutnya dianalisis dengan menggunakan analisis regresi linier berganda. Hasil penelitian menunjukkan bahwa media sosial, word of mouth dan physical environment berpengaruh signifikan pada proses keputusan pembelian. Berdasarkan hasil analisis regresi berganda dapat diketahui bahwa nilai koefisien regresi terbesar yaitu physical environment, hal ini berarti physical environment merupakan variabel yang berpengaruh dominan terhadap proses keputusan pembelian, diikuti oleh variabel word of mouth dan media sosial.

Keywords: Keputusan pembelian, Physical Environment, Word of Mouth

JEL Classification: M31 


\section{Latar Belakang}

Trend startup digital ikut menghadirkan banyak peluang bisnis baru. Salah satunya kehadiran coworking space atau coworking coffee shop. Ruang kerja kekinian yang mengakomodasi kebutuhan pekerja yang fleksibel. Di Indonesia, coworking space pertama kali hadir di Bandung pada tahun 2010 dan terus berkembang di kota-kota lainnya di Indonesia, termasuk di kota Malang. Coworking Space bernuansa kebun pertama yang dipadupadankan dengan coffee shop di kota Malang adalah Gartenhaus Coworking Coffee Shop yang beralamatkan di Jalan Kenanga Indah No. 1 Jatimulyo Kecamatan Lowokwaru Kota Malang.

Berada di lokasi perkampungan yang tidak strategis, Gartenhaus memulai dengan jam buka yang tidak tentu dan pengunjung yang hanya berasal dari kalangan teman, pemilik Gartenhaus hanya mengandalkan komunikasi dari mulut ke mulut atau word of mouth untuk menginformasikan keberadaan coworking space miliknya. Word of mouth atau pemasaran dengan perantara pengunjung satu ke pengunjung lainnya ini disampaikan secara lisan tentang pengalaman menggunakan jasa atau produk Gartenhaus (Kotler \& Keller, 2009). Word of mouth dianggap pemilik Gartenhaus sebagai sarana yang dapat mempengaruhi keputusan pembelian calon pengunjung. Apabila calon pengunjung tidak yakin tentang keuntungan dari layanan yang akan mereka terima, mereka bisa tidak melakukan pembelian di Gartenhaus sama sekali (Brown et al., 2005).

Setelah pengunjung berjumlah lebih banyak maka pemilik Gartenhaus mulai menentukan jam operasional yang tetap yaitu jam 14.00 sampai dengan jam 24.00 WIB dari hari Selasa sampai dengan hari Minggu. Karena mayoritas pengunjung adalah mahasiswa maka pemilik Gartenhaus mulai berpromosi secara online mengingat pencarian informasi yang dilakukan para mahasiswa saat ini lebih banyak melalui media online dengan tujuan agar Gartenhaus lebih dikenal lagi. Platform yang dipilih adalah Instagram. Instagram adalah platform media sosial yang populer dengan cara memposting foto. Pengguna Instagram dapat mengunggah foto, sunting foto, dan membagi foto kepada pengguna lainnya (Miles, 2014). Pemilihan platform inipun bukan berdasarkan riset pasar sebelumnya, namun hanya dengan pertimbangan sekarang sedang trend penggunaan Instagram. Konten Instagram Gartenhaus selain foto-foto dari koleksi pemilik, konten juga didapatkan dengan cara repost dari konten Instagram para pengunjung. Pemilik hanya memastikan konten terus diupdate tanpa mempertimbangkan bahwa konten dapat mengubah pemikiran konsumen dalam membuat keputusan akhir terhadap penolakan atau pemilihan suatu tempat (Neuhofer, 2017).

Pengelolaan yang tidak melalui pembuatan perencanaan bisnis dan riset sebelumnya, serta lokasi Gartenhaus yang tidak strategis karena berada di perkampungan tapi memiliki jumlah pengunjung rata-rata 50 orang sampai 70 orang per hari inilah yang menarik buat peneliti. Proses keputusan pengunjung untuk memilih layanan dan produk Gartenhaus yang dimulai dari pengenalan kebutuhan, pencarian informasi kemudian evaluasi alternatif, serta dilanjutkan dengan keputusan berkunjung dan melakukan pembelian sampai dengan perilaku pasca pembelian (Kotler, 2009) inilah yang belum diketahui secara pasti oleh pemilik Gartenhaus. Bahkan pemilik juga belum mengetahui faktor utama yang membuat tempatnya ramai pengunjung. Kedatangan pengunjung apakah dipengaruhi oleh promosi di Instagram, karena dipengaruhi oleh cerita dari pengunjung sebelumnya atau karena tempat dengan konsep natural ambience yang diusung oleh Gartenhaus. Ambience adalah salah satu bagian dari marketing strategi selain produk, harga, tempat, dan promosi (Zeithaml \& Bitner, 2010). Selain Ambience factors, marketing strategi juga dapat melalui Design factors yaitu keindahan tempat dan tata letak ruang, serta Social factors yaitu keberadaan pengunjung lain serta layanan dari staff yang dikembangkan dan diklasifikasikan oleh Baker (1986).

Berlatar belakang pertanyaan-pertanyaan dari pemilik inilah maka penelitian ini dilaksanakan dengan mengambil permasalahan pengaruh media sosial, word of mouth dan physical environment terhadap proses keputusan pembelian di Gartenhaus Coworking Coffee Shop Malang. Tujuan yang ingin di capai dari penelitian ini adalah mendeskripsikan dan menganalisis pengaruh media sosial, word of mouth, physical environment dan terhadap proses keputusan pembelian.

\section{Kajian Literatur}

\section{Media Sosial}

Pembuatan konten atau content creation dengan kualitas tinggi akan menjadi salah satu variabel dari media sosial marketing. Selain content creation, variabel keefektifan media sosial sebagai alat marketing komunikasi lainnya yaitu content sharing, connecting, dan community building (Gunelis, 2011). Content sharing membantu pebisnis memperluas jaringan dan target konsumen secara online. Kegiatan content sharing dapat mengarah ke penjualan langsung ataupun tidak langsung. Sedangkan connecting menjadikan pemberi informasi dan penerima informasi yang memiliki minat yang sama saling terhubung dan menghasilkan lebih banyak bisnis. Variabel 
Community Building bertujuan untuk mencari target konsumen yang memiliki ketertarikan terhadap produk dan jasa yang ditawarkan. Dari keempat variabel yang mendukung keefektifan media sosial yaitu content creation, content sharing, connecting dan community (Gunelis, 2011), peneliti mengambil tiga variabel sebagai indikator dari media sosial yaitu content creation, content sharing dan connecting. Media Sosial Marketing yang dilakukan oleh suatu bisnis dapat mempengaruhi pemikiran seseorang yang akan berdampak pada pemikiran orang lainnya secara lebih luas sebelum melakukan keputusan pembelian (Gunelis, 2011)

\section{Word of mouth (WOM)}

Word of mouth (WOM) adalah produk informasi yang disalurkan dari orang ke orang. Pemasaran melalui perantara orang ke orang ini dapat disampaikan secara lisan, tulisan, ataupun menggunakan alat komunikasi elektronik tentang pengalaman menggunakan jasa atau produk (Kotler and Keller, 2009). Karena konsumen mendapatkan informasi dari orang yang dikenal maka word of mouth bisa diandalkan dan bisa dipercaya jika dibandingkan dengan alat promosi pemasaran lainnya (Solomon, 2002). Semakin positif informasi tentang produk atau jasa yang disampaikan, maka makin besar keinginan untuk mengadaptasi penggunaan produk atau jasa dari merek tersebut. Word of mouth positif ditemukan tujuh kali lebih efektif dibandingkan iklan di koran dan majalah, empat kali lebih efektif dibandingkan penjualan perseorangan, dan dua kali lebih efektif dibandingkan iklan di radio yang mempengaruhi konsumen untuk mengganti pilihan produk atau jasa (Katz et al., 2005).

\section{Physical environment}

Baker (1986) menyebutkan bahwa Physical environment yang juga menjadi faktor penting dalam bisnis pelayanan. Baker (1986) menyebutkan ada tiga komponen dasar dari physical environment yaitu ambience, design dan social factors. Ambience meliputi fasilitas yang dirasakan oleh pengunjung yaitu aroma, suara, kebersihan serta kualitas udara. Sedangkan untuk design terbagi menjadi dua dimensi, yang pertama dimensi keindahan yang meliputi pemilihan warna, arsitektur, pemilihan materi, pemilihan tekstur dan pola, style dan asesoris. Sedangkan dimensi kedua dari design adalah dimensi fungsi yang meliputi layout, kenyamanan, privacy dan signage. Untuk komponen dasar social factors dalam physical environment juga terbagi menjadi dua dimensi yaitu audience atau pengunjung yang lain dan staff pelayanan. Komponen audience dan staff pelayanan adalah penampilan, cara melayani dan sikap. Dari ketiga komponen dasar dari physical environmet yaitu ambience, design factors dan social factors inilah yang akan menjadi indikator dari variabel physical environment di dalam penelitian kali ini.

\section{Keputusan Pembelian}

Keputusan pembelian adalah tindakan dari konsumen untuk mau membeli atau tidak terhadap produk (Kotler, 2002). Dari berbagai faktor yang mempengaruhi konsumen dalam melakukan pembelian suatu produk atau jasa, biasanya konsumen selalu mempertimbangkan kualitas, harga dan produk yang sudah dikenal oleh masyarakat. Pengenalan Masalah adalah proses dimana konsumen menemukan masalah atau kebutuhan. Kebutuhan yang muncul dapat disebabkan oleh rangsangan internal (dari dalam diri) dan rangsangan eksternal (dari lingkungan). Setelah mengenali masalah, konsumen akan memasuki tahapan berikutnya yaitu Pencarian Informasi. Di tahapan pencarian informasi, konsumen akan mencari informasi sebanyak-banyaknya untuk memenuhi kebutuhannya. Jika konsumen dan jasa yang dapat memenuhi kebutuhan berada dalam jangkauan, maka memungkinkan konsumen untuk menggunakan jasa tersebut. Namun bila tidak, konsumen dapat menyimpan kebutuhan dalam ingatan atau melakukan pencarian informasi lain yang berhubungan dengan kebutuhan tersebut. Konsumen dapat memperoleh informasi dari beragam sumber yaitu sumber pribadi (keluarga, teman dan tetangga), sumber komersial (iklan), sumber publik (media massa), dan sumber pengalaman (menggunakan jasa). Setelah serangkaian informasi diperoleh, konsumen akan memasuki tahapan Evaluasi Alternatif, dimana konsumen akan dihadapkan dengan beragam pilihan jasa yang akan digunakannya. Bagaimana konsumen memilih jasa yang sesuai dengan kebutuhannya akan tergantung pada masing-masing individu dan situasi penggunaan yang spesifik. Apabila pilihan telah ditemukan, maka konsumen akan memasuki tahapan Keputusan Pembelian. Pada umumnya keputusan pembelian yang dilakukan adalah menggunakan jasa yang disukai. Namun ada dua faktor yang muncul antara niat menggunakan jasa dan keputusan untuk menggunakan jasa yaitu sikap orang lain dan situasi yang tidak diharapkan. Konsumen umumnya membentuk niat menggunakan jasa berdasarkan faktor harga dan manfaat produk, tetapi peristiwa-peristiwa yang tidak 
diharapkan juga bisa mengubah niat menggunakan jasa. Jadi pilihan dan niat untuk menggunakan jasa tidak selalu berakhir dengan keputusan menggunakan jasa yang sudah dipilih.

\section{Kerangka Konseptual Variabel Penelitian}

Peneliti akan meneliti tentang pengaruh media sosial, word of mouth dan physical environment terhadap keputusan pembelian di Gartenhaus Coworking Coffee Shop Malang. Pertama yang akan dilakukan adalah meneliti masing-masing pengaruh secara parsial dan simultan variabel $X$ terhadap variabel $Y$. Adapun model kerangka konseptual penelitian ini dapat dilihat pada gambar berikut :

Gambar 1. Kerangka Konseptual Penelitian

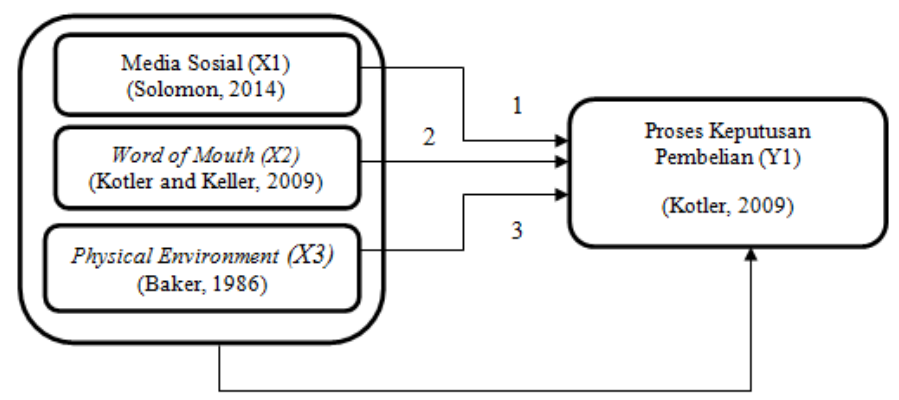

Sumber : Kajian Teoritis Diolah (2020)

Berdasarkan kerangka konseptual penelitian yang telah disusun, maka hipotesis di dalam penelitian ini adalah sebagai berikut:

$\mathrm{H} 1$ : Media Sosial berpengaruh signifikan pada proses keputusan pembelian

$\mathrm{H} 2$ : Word of Mouth berpengaruh signifikan pada proses keputusan pembelian

H3 : Physical Environment berpengaruh pada proses keputusan pembelian

$\mathrm{H} 4$ : Physical Environment berpengaruh dominan pada proses keputusan pembelian

\section{Metode Penelitian}

Jenis penelitian ini adalah penelitian kuantitatif dengan pendekatan eksplanatory. Populasi di dalam penelitian ini adalah seluruh pengunjung yang ada di Gartenhaus Coworking Coffee Shop Malang. Peneliti menggunakan teknik sampling slovin dengan menggunakan rata-rata jumlah pengunjung bulanan sebagai dasar perhitungan dan ditemukan 138 responden yang digunakan di dalam penelitian ini. Penelitian ini menggunakan kuesioner untuk memperoleh data dari responden. Hasil kuesioner tersebut diuji validitas dan reliabilitasnya terlebih dahulu, dan selanjutnya dianalisis dengan menggunakan teknik analisis regresi linear berganda.

\section{Hasil}

Sebelum dilakukan uji hipotesis, di dalam teknik analisis regresi linear berganda mensyaratkan uji asumsi klasik. Hasil uji normalitas menunjukkan bahwa data yang diperoleh peneliti dari kuesioner berdistribusi normal yang dibuktikan baik dari grafik hitogram maupun grafik p-plot. Selanjutnya, untuk uji multikolinieritas tidak ditemukan masalah multikolinieritas antar variabel bebas yaitu variabel media sosial, word of mouth, dan physical environment . Terakhir adalah uji heterokedastisitas yang ditunjukkan oleh grafik scatterplot dimana titik-titik yang ada di dalam grafik tersebut tersebar secara acak. Berdasarkan hasil uji asumsi klasik tersebut maka dapat disimpulkan bahwa model penelitian ini memenuhi syarat untuk dilakukan analisis regresi linear berganda. Berikut adalah hasil dari uji asumsi klasik di dalam penelitian ini.

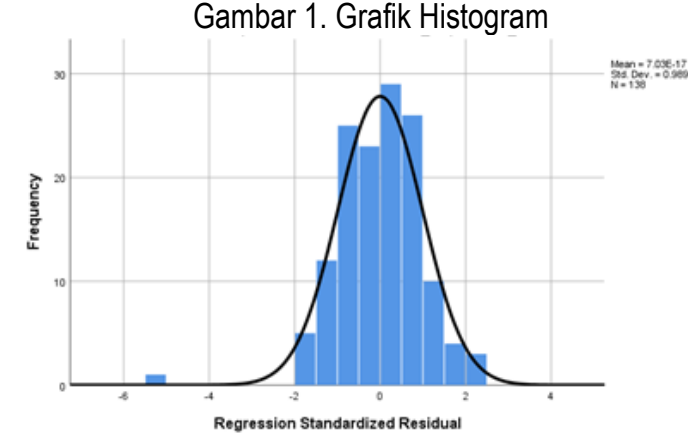

Sumber : Data Sekunder Diolah (2020)

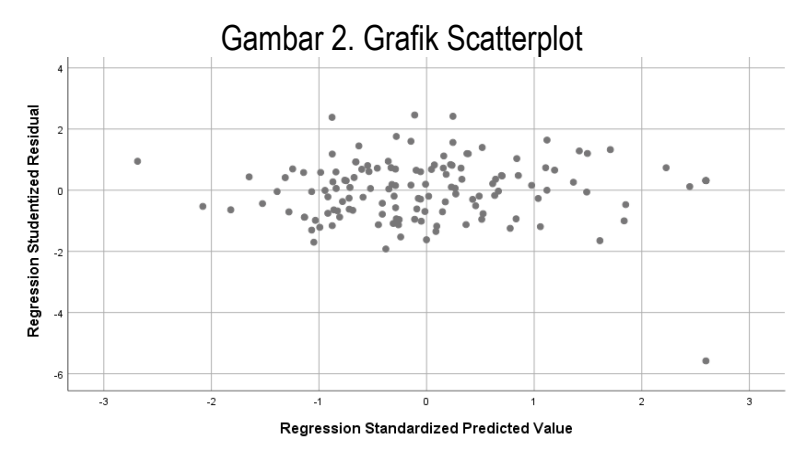

Sumber : Data Sekunder Diolah (2020) 
Berdasarkan hasil uji regresi linear berganda diperoleh persamaan regresi sebagai berikut :

\section{$Y=9,482+0,345 \times 1+0,473 \times 2+0,601 \times 3$}

Dari persamaan regresi diatas dapat dijelaskan jika variabel media sosial meningkat satu satuan dengan asumsi variabel word of mouth dan physical environment tetap maka variabel proses keputusan pembelian juga akan meningkat sebesar 0,345 . Selanjutnya jika variabel word of mouth meningkat satu satuan dengan asumsi variabel media sosial dan physical environment tetap maka variabel proses keputusan pembelian juga meningkat sebesar 0,473. Sedangkan jika variabel physical environment meningkat satu satuan dengan asumsi variabel media sosial dan word of mouth tetap maka variabel proses keputusan pembelian juga meningkat sebesar 0,601. Dapat disimpulkan bahwa keseluruhan variabel bebas yang diteliti di dalam penelitian ini memiliki pengaruh positif terhadap variabel terikat.

Dari data hasil uji $t$ ditemukan bahwa $t$ hitung untuk variabel media sosial sebesar 2,697 sedangkan $t$ hitung untuk variabel word of mouth sebesar 3,533 dan t hitung untuk variabel physical environment sebesar 4,940 . Untuk mengetahui variabel independen yang berpengaruh dominan terhadap variabel dependen, maka dapat diamati melalui t hitung yang memiliki nilai terbesar. Berdasarkan hasil uji t, menunjukkan bahwa variabel physical environment memiliki nilai t hitung yang lebih besar yaitu 4,940 jika dibandingkan dengan variabel media sosial yang memiliki t hitung sebesar 2,697 maupun variabel word of mouth yang memiliki thitung sebesar 3,533. Dengan demikian maka hipotesis kedua ditolak secara statistik atau word of mouth tidak berpengaruh dominan pada proses keputusan pembelian di Gartenhaus Coworking Coffee Shop. Sedangkan yang memiliki pengaruh dominan adalah variabel physical environment pada proses keputusan pembelian di Gartenhaus Coworking Coffee Shop.

Koefisien determinasi atau $R$ square di dalam penelitian ini ditemukan sebesar 0,562 atau $56,2 \%$. Dari nilai $R$ square ini dapat dijelaskan bahwa besarnya kontribusi pengaruh variabel independen yaitu media sosial, word of mouth, dan physical environment terhadap variabel dependen yaitu proses keputusan pembelian secara bersama-sama atau simultan adalah sebesar $56,2 \%$. Artinya ada $43,8 \%$ variabel-variabel independen lain yang dapat mempengaruhi variabel dependen yaitu proses keputusan pembelian yang tidak dibahas dalam penelitian ini.

\section{Pembahasan}

\section{Pengaruh Media Sosial Terhadap Keputusan Pembelian}

Berdasarkan hasil uji t diketahui bahwa nilai koefisien pengaruh media sosial terhadap keputusan pembelian sebesar 0,345. Hal tersebut menunjukkan bahwa media sosial memiliki pengaruh positif terhadap keputusan pembelian. Selanjutnya, hasil thitung untuk variabel media sosial adalah sebesar 2,697, lebih besar dari t tabel yaitu 1,656. Dengan demikian dapat disimpulkan bahwa media sosial berpengaruh positif signifikan terhadap keputusan pembelian. Hasil tersebut sesuai dengan pendapat Solomon (2014) dari yang digunakan di dalam penelitian ini. Hasil mendukung hasil penelitian sebelumnya yang dilakukan oleh Neuhofer (2017) yang juga membuktikan bahwa media sosial memiliki peran penting salam mempengaruhi perilaku konsumen.

Media sosial terbentuk dari content creation, content sharing dan connecting (Gunelis, 2011). Kontribusi utama keefektifan media sosial adalah content creation atau pembuatan konten. Pembuatan konten yang bernilai, konsisten, dan relevan dalam bentuk teks, video atau audio yang bernilai tambah adalah proses secara langsung dan tidak langsung dalam mempromosikan bisnis (Gunelis, 2011). Hal ini terlihat juga dari para pengunjung Gartenhaus Coworking Coffee Shop yang mengatakan setuju bahwa konten instagram Gartenhaus menarik, diperbaharui secara rutin serta menggunakan hashtag yang mempermudah pencarian. Hasil penelitian ini menunjukkan bahwa peran media sosial cukup penting dalam mempengaruhi keputusan pembelian oleh pelanggan. Terlebih di era digital, calon pelanggan memiliki kebiasaan untuk melihat media sosial tempat tujuannya terlebih dahulu sebelum memutuskan untuk mendatangi atau membeli produk di tempat tujuannya. Salah satu platform media sosial yang saat ini digunakan oleh Gartenhaus Coworking Cofee Shop adalah Instagram. Sebagai platform yang mengutamakan postingan dalam bentuk foto, Instagram bagi Gartenhaus adalah alat pemasaran bisnis. Dengan konten berkualitas tinggi dan menarik yang diperbaharui secara rutin, Instagram Gartenhaus menjadi sarana menyampaikan informasi kepada pelanggan (Gunelis, 2011). 
Peningkatan kualitas media sosial dan pemanfaatan media sosial sebagai sarana pemasaran terbukti memberikan dampak yang positif dan signifikan di dalam meningkatkan keputusan pembelian pelanggan.

\section{Pengaruh Word Of Mouth terhadap Keputusan Pembelian}

Berdasarkan hasil uji t diketahui bahwa nilai koefisien pengaruh word of mouth terhadap keputusan pembelian sebesar 0,473 . Hal tersebut menunjukkan bahwa word of mouth memiliki pengaruh positif terhadap keputusan pembelian. Selanjutnya, hasil thitung untuk variabel word of mouth adalah sebesar 3,533 , lebih besar dari t tabel yaitu 1,656. Dengan demikian dapat disimpulkan bahwa word of mouth berpengaruh positif signifikan terhadap keputusan pembelian. Hasil tersebut sesuai dengan pendapat Kotler dan Keller (2009) dari yang digunakan di dalam penelitian ini. Hasil penelitian ini mendukung penelitian yang dilakukan sebelumnya oleh Basri et al (2015) yang menyebutkan bahwa word of mouth adalah kunci sukses sebuah organisasi. Selain itu di dalam penelitian Brown et al (2005) juga mengatakan bahwa word of mouth adalah komunikasi yang sangat berarti bagi konsumen.

Word of mouth terbentuk dari tahapan membicarakan, merekomendasikan, dan mendorong (Babin, 2005). Kontribusi utama keefektifan word of mouth adalah tahap merekomendasikan. Pengunjung Gartenhaus Coworking Coffee Shop yang merasa puas dengan produk dan layanan dari Gartenhaus akan merekomendasikan kepada orang lain. Hal ini terlihat dari para pengunjung Gartenhaus yang mengatakan setuju untuk merekomendasikan Gartenhaus kepada orang lain. Hasil penelitian ini menunjukkan bahwa peran word of mouth cukup penting dalam mempengaruhi keputusan pembelian oleh pelanggan. Pelanggan yang sebelumnya pernah mengunjungi atau mencoba produk memiliki kebiasaan untuk membagikan pengalaman dan pendapat mengenai tempat atau produk yang dicobanya tersebut ke rekan atau bahkan dibagikan di media sosialnya. Hal tersebut terbukti efektif di dalam mempengaruhi keputusan pembelian calon pelanggan.

\section{Pengaruh Physical Environment terhadap Keputusan Pembelian}

Berdasarkan hasil uji $t$ diketahui bahwa nilai koefisien pengaruh physical environment terhadap keputusan pembelian sebesar 0,601. Hal tersebut menunjukkan bahwa physical environment memiliki pengaruh positif terhadap keputusan pembelian. Selanjutnya, hasil thitung untuk variabel physical environment adalah sebesar 4,940 , lebih besar dari $t$ tabel yaitu 1,656. Dengan demikian dapat disimpulkan bahwa physical environment berpengaruh positif signifikan terhadap keputusan pembelian. Hasil tersebut sesuai dengan pendapat Kotler dan Baker (1986) dari yang digunakan di dalam penelitian ini. Hasil ini juga mendukung penelitian sebelumnya dari Hattawijitukul (2017) yang menyebutkan bahwa design, ketenangan, kebersihan dan sikap staff yang menjadi bahan pertimbangan konsumen saat memilih coworking coffee shop.

Physical environment terbentuk dari komponen ambience, design, dan social (Baker, 1986). Kontribusi utama keefektifan physical environment adalah ambience. Ambience meliputi fasilitas yang dirasakan oleh pengunjung yaitu aroma, suara, kebersihan serta kualitas udara (Baker, 1986). Area Gartenhaus yang bersih dan menyenangkan serta didukung oleh tanaman-tanaman di kebun membuat pengunjung merasa nyaman berada di Gartenhaus Coworking Coffee Shop. Hasil penelitian ini menunjukkan bahwa peran physical environment cukup penting dalam mempengaruhi keputusan pembelian oleh pelanggan. Lingkungan atau lokasi tempat tujuan pelanggan menjadi pertimbangan penting di dalam mempengaruhi keputusan pembelian atau kunjungan oleh pelanggan. Di era sekarang ini, tempat yang instagramable menjadi daya tarik tersendiri bagi pelanggan. Lokasi yang menarik membuat pelanggan tertarik untuk mendatangi lokasi tersebut dan memutuskan untuk berkunjung dan melakukan pembelian.

\section{Pengaruh Dominan Physical Environment terharap Keputusan Pembelian}

Berdasarkan hasil uji $t$ diketahui bahwa physical environment memiliki nilai koefisien tersbesar di dalam mempengaruhi keputusan pembelian dengan nilai 0,601. Diikuti oleh word of mouth yaitu sebesar 0,473 , dan media sosial yaitu 0,345 . Berdasarkan hasil tersebut dapat disimpulkan bahwa physical environment memiliki pengaruh dominan di dalam mempengaruhi keputusan pembelian pelanggan dibandingkan dengan word of mouth dan media sosial. Penting bagi pemilik usaha untuk dapat senantiasa meningkatkan physical environment dari usahanya karena hal tersebut terbukti paling berpengaruh di dalam mempengaruhi keputusan pembelian calon pelanggan.

\section{Kesimpulan}

Berdasarkan hasil penelitian yang telah dilakukan, dapat disimpulkan bahwa media sosial, word of mouth dan physical environment berpengaruh positif dan signifikan terhadap keputusan pembelian baik secara parsial maupun simultan. Selanjutnya, diketahui juga bahwa physical environment memiliki pengaruh dominan di antara variabel bebas lain di dalam mempengaruhi keputusan pembelian pelanggan. Penting bagi pemilik usaha untuk 
senantiasa terus meningkatkan ketiga variabel tersebut agar pelanggan semakin tertarik untuk melakukan keputusan pembelian di tempat usahanya.

Berdasarkan hasil penelitian ini, dari segi media sosial, pengelola Instagram Gartenhaus dapat meningkatkan kualitas foto dan video yang diposting. Pengambilan foto serta video dapat dilakukan oleh tim kreatif dari Gartenhaus sehingga tidak hanya repost konten dari pengunjung. Selanjutnya, manajemen Gartenhaus disarankan untuk memperhatikan kualitas layanan dan produk yang ditawarkan kepada pengunjung agar menghasilkan pengalaman yang positif pada pengunjung. Karena dengan pengalaman yang positif maka word of mouth positif juga yang akan tersampaikan kepada orang lain yang dikenal. Dari segi physical environment, Marketer Gartenhaus dapat melakukan riset agar dapat menemukan ambience atau atmosphere seperti yang diinginkan oleh konsumen, utamanya agar dapat meningkatkan pembelian. Untuk peneliti selanjutnya dapat menambahkan variabel lain yang belum diteliti di dalam penelitian ini baik variabel bebas maupun variabel mediasi.

\section{References}

Babin, Barry J., L Kong Kie, Kum, EunFu and Griffin, Mitch. (2005).Modelling consumer satisfaction \& word of mouth communication : Restorant Petronage Korea. Journal of Services Marketing Vol.19 pp 133-139. Baker, Julie. The Role of The Environment in Marketing Sevices : The Consumer Perspective. Chicago, IL : American Marketing Association

Brown, T.J., Barry, T.E., Dacin, P.A. \& Gunst, R.F. (2005). Spreading the word : investigating antecendents of consumers' positive word-of-mouth intentions and behaviour in retailing context. Journal of Academy of Marketing Science.

Gunelis, Susan. (2011). 30 Minute Social Media Marketing. United States : McGraw Hill.

Hattawijitkul, Manita, Jarinto, Krit. (2017). Factors affecting consumers' decision to use coworking coffee shop: a case study in Bangkok and Chon Buri Province.

Katz, E., Lazarsfeld, P.F. (2005). Personal influence: the part played by people in the flow of mass communication. New York : Routledge

Kotler, Philip. (1973). Atmosphere as a Marketing Tool. Journal of Retailing.

Kotler, Philip. (2002). Manajemen Pemasaran Jilid 1 Edisi Milenium. Jakarta : Prehallindo.

Kotler, Phillip dan Keller, Kevin Lane. (2009). Manajemen Pemasaran Edisi 13 Jilid 1. Jakarta: PT. Gelora Aksara Pratama

Miles, Jason G. (2014). Instagram Power : Build Your Brand and Reach More Customers with the Power of Picture. McGraw Hill Education.

Neuhofer, Barbara. (2017). The influence of social media on the consumer's hotel decision journey. Journal of Hospitality and Tourism Technology.

Solomon, Michael R. (2002). Fifth Edition Consumer Behavior Buying, Having, And Being. New Jersey : Prentice Hall , Inc.

Solomon, Michael R., Tuten, Tracy L., (2014). Social Media Marketing. SAGE.

Zeithaml, Valarie A., Gemler, Dwayne D. (2010). Services marketing strategy. Wiley International Encyclopedia of Marketing. 